\title{
PENGEMBANGAN APLIKASI LOCATION BASED SERVICE UNTUK INFORMASI DAN PENCARIAN LOKASI PARIWISATA DI KOTA CIMAHI BERBASIS ANDROID
}

\author{
Nova Agustina ${ }^{1)}$, Slamet Risnanto ${ }^{2)}$, Irwin Supriadi ${ }^{3)}$ \\ ${ }^{122) 3)}$ Program Studi Teknik Informatika Sekolah Tinggi Teknologi Bandung \\ Jl. Soekarno Hatta no. 378 Bandung \\ nova@ sttbandung.ac.id ${ }^{1)}$, slamet_risnanto@yahoo.co.id ${ }^{2)}$,irwinshared@gmail.com ${ }^{3}$
}

\begin{abstract}
Abstrak
Pariwisata adalah salah satu sektor yang dapat diandalkan sebagai sumber devisa negara. Dalam perjalanan untuk mencari lokasi terdekat ke lokasi pariwisata yang diinginkan, untuk mencari lokasi pariwisata yang ada di Kota Cimahi melalui perangkat mobile menjadi sangat penting mengingat wisatawan yang sulit untuk menemukan lokasi pariwisata. Location based service (LBS) merupakan salah satu layanan informasi yang memanfaatkan kemampuan penunjuk lokasi pada perangkat mobile dan dapat diakses melalui jaringan mobile. Tujuan dari penelitian ini adalah untuk menghasilkan suatu aplikasi Location Based Service pada perangkat mobile Android yang mampu membantu untuk mencari informasi dan lokasi pariwisata dari lokasi user berikut rute yang dapat ditempuh menuju lokasi pariwisata tersebut.
\end{abstract}

Berdasarkan hasil dari implementasi dan ujicoba yang dilakukan maka dapat ditarik kesimpulan bahwa aplikasi Location Based Service yang dibuat dapat membantu user untuk mencari informasi, lokasi pariwisata dan juga menentukan rute yang dapat ditempuh menuju lokasi pariwisata tersebut.

Kata kunci: Location Based Service (LBS), pariwisata, mobile, Android

\begin{abstract}
Tourism is one of the sectors that can be relied upon as a source of foreign exchange of the country. On the way to find the nearest location to the location of the desired tourism, to search for the location of the exiting tourism in Cimahi throught mobile device becomes very important given the tourists harder to find the locations of tourism.
\end{abstract}

Location based service (LBS) is one of the information services which is using the ubility of locations tracking on mobile phone and it can be accessed through mobile networks. The purpose of this paper is to produce a Location Based Service applications on Android mobile devices that can help to find information and locations of tourism from the user's location along with the routes of the tourism.

Based on the results of implementation and some test that have been done, it can be concluded that the Location Based Service application helps the users to find information, tourism's location and also helps them to decide with route to the tourism that can be taken bests.

Keywords: Location Based Service (LBS), tourism, mobile, Android

\section{Pendahuluan}

\section{I.1 Latar Belakang}

Salah satu sektor yang dapat diandalkan sebagai sumber devisa negara adalah sektor pariwisata. Jawa Barat memiliki kegiatan pariwisata yang cukup potensial untuk menunjang pembangunan daerah. Paling tidak, dapat diandalkan sebagai sumber pendapatan di Indonesia. Jumlah kunjungan wisatawan ke obyek wisata di Jawa Barat pada tahun 2011 sebanyak 28.300.085 dimana 844.557 (2,98\%) merupakan kunjungan wisatawan mancanegara dan $27.455 .525 \quad(97,02 \%)$ merupakan wisatawan nusantara (BPS Provinsi Jawa Barat, 2012).

Kota Cimahi merupakan sebuah kota di provinsi Jawa Barat, Indonesia.Kota ini terletak diantara Kabupaten Bandung dan Kabupaten Bandung Barat. Kota Cimahi menduduki peringkat terakhir 
kunjungan wisatawan dibandingkan kota lainnya di Jawa Barat dengan memiliki total jumlah kunjungan wisatawan sebesar 2.400 pengunjung dibawah jumlah kunjungan wisatawan Kota Depok, yakni sebesar 6.275 pada tahun 2011 (BPS Provinsi Jawa Barat, 2012).

Di Indonesia, statistik pengguna Android pada tahun 2014 mendominasi peredaran smartphone di tanah air dengan pembagian pasar 59,91\% (Growth From Knowladge, 2015). Hal ini menjadi salah satu penyebab pengembang di Indonesia beralih untuk mengembangkan aplikasi Android yang telah mendominasi pasaran smartphone. Aplikasi-aplikasi yang ditawarkan memiliki fungsi utama untuk memenuhi kebutuhan pengguna, diantaranya memuaskan keinginan pengguna, memudahkan pengguna mendapatkan informasi yang up to date hingga mencari lokasi tujuan yang diinginkan pengguna.

LBS (Location Based Service) adalah layanan informasi yang dapat diakses melalui mobile device dengan menggunakan jaringan (Safaat, 2013). Dengan memanfaatkan teknologi GPS, sistem LBS ini dapat digunakan untuk mengetahui posisi berdasarkan titik geografis dari lokasi pengguna dan lokasi yang dituju. Android merupakan salah satu platform smartphone terbaru yang dapat digunakan untuk mengimplementasikan sistem LBS (Location Based Service).

Dalam upaya memudahkan wisatawan mencari lokasi tempat wisata di Kota Cimahi, peneliti tertarik untuk membuat aplikasi tentang pencarian lokasi parawisata di Kota Cimahi dengan judul "Aplikasi Location Based Service Untuk Informasi dan Pencarian Lokasi Pariwisata di Kota Cimahi Berbasis Android".

\section{I.2 Identifikasi Masalah}

Berdasarkan latar belakang diatas, peneliti mengidentifikasikan masalah diantaranya sebagai berikut:

1. Lokasi tempat wisata di Kota Cimahi tidak banyak diketahui keberadaannya oleh wisatawan.

2. Pengguna peta kertas harus mengurutkan rute jalan yang harus ditempuh dari lokasi keberadaan wisatawan tersebut ke tempat tujuan wisata di Kota Cimahi.
3. Peta kertas tidak memberikan saran rute jalan yang terdekat ke tempat wisata Kota Cimahi untuk dilalui.

\section{I.3 Maksud dan Tujuan Penelitian}

Penelitian ini dilakukan dengan maksud sebagai berikut:

1. Membangun aplikasi location based service untuk membuat wisatawan mengetahui lokasi wisata di Kota Cimahi.

2. Memberikan informasi rute jalan yang dapat ditempuh ke tempat wisata di Kota Cimahi sesuai dengan urutannya.

3. Memberikan saran kepada wisatawan untuk memilih rute jalan terdekat ke tempat wisata tujuan yang diinginkan di kota Cimahi.

Tujuan dari penulisan artikel ini adalah sebagai salah satu upaya untuk berbagi pengetahuan dan hasil penelitian sebagai bahan pengembangan yang lebih baik.

\section{I.4 Ruang Lingkup}

Ruang lingkup masalah yang akan dibahas pada penelitian ini adalah:

1. Bagaimana membangun aplikasi untuk memberikan informasi dan pencarian lokasi wisata di Kota Cimahi.

2. Aplikasi memberikan urutan rute jalan yang dapat ditempuh ke tempat wisata di Kota Cimahi.

3. Memberikan saran rute jalan terdekat ke tempat wisata di Kota Cimahi.

4. Aplikasi ini dapat digunakan pada Android 4.2.2 minimal (Kitkat) dengan API (Application Programming Interface) 19.

\section{KAJIAN LiterATUR}

\section{II.1 Location Based Service (LBS)}

Location Based Service (LBS) mengacu pada "sekumpulan aplikasi yang mengeksplorasi pengetahuan / informasi dari lokasi geografis perangkat mobile untuk mendapatkan layanan berdasarkan informasi tersebut". (IAMAI, 2008)

Pemanfaatan LBS memudahkan pengguna perangkat mobile mengatur dan memilih layanan 
sesuai kebutuhan dan dapat dimanfaatkan untuk memberikan berbagai layanan seperti informasi kondisi lingkungan (kemacetan lalu lintas, cuaca, lokasi fasilitas umum terdekat), maupun promosi produk dan jasa.

Pemanfaatan LBS pada sistem operasi perangkat mobile android dimungkinkan dengan adanya dukungan dua unsur utama berikut:

1. Location Manager (API Maps) Menyediakan tool atau source untuk LBS, Application Progrogram Interface (API). Maps menyediakan fasilitas untuk menampilakan, memanipulasi maps atau peta beserta featurefeature lainnya seperti tampilan satelit, street (jalan), maupun gabungannya. Paket ini berada com.google.android.map.

2. Location Provider (API Location) Menyediakan teknologi pencarian lokasi yang digunakan oleh device atau perangkat. API Location berhubungan dengan data GPS (Global Positioning System) dan data lokasi real-time. API Location berada pada paket android yaitu dalam paket android.location. Dengan Location Manager, kita dapat menentukan lokasi kita saat ini, Track gerakan atau perpindahan, serta kedekatan dengan lokasi tertentu dengan mendeteksi perpindahan

\section{II.2 Pariwisata}

Menurut Undang-Undang RI nomor 10 tahun 2009 tentang kepariwisataan dijelaskan bahwa wisata adalah kegiatan perjalanan yang dilakukan oleh seseorang atau sekelompok orang dengan mengunjungi tempat tertentu untuk tujuan rekreasi, pengembangan pribadi, atau mempelajari keunikan daya tarik wisata yang dikunjungi dalam waktu sementara (Sumber: www.unikom.ac.id). Tabel 1 menampilkan klasifikasi usaha pada industri pariwista.

Tabel 1. Kalisifikasi Usaha pada Industri Pariwisata

\begin{tabular}{ll}
\hline \hline Klasifikasi & Usaha \\
\hline \hline Akomodasi & $\begin{array}{l}\text { Hotel, Olahraga, Penjualan Pakaian } \\
\text { dan Areal Rekreasi. }\end{array}$ \\
Pelayanan & Restoran dan penjual makanan kaki \\
Makanan & lima yang terpusat. \\
Kebudayaan dan & Museum, Taman Hiburan, Teater, \\
Entertainment & Adat dan Entertainment \\
\hline \hline
\end{tabular}

\section{II.3 Google Maps API}

Menurut Sugiarto (2013:3) API atau Application Programming Interface merupakan suatu dokumentasi yang terdari dari interface, fungsi, kelas, struktur dan sebagainya untuk membangun sebuah perangkat. Dengan adanya API ini, maka memudahkan programmer untuk membongkar suatu software untuk kemudian dapat dikembangkan atau diintegrasikan dengan perangkat lunak lain. API dapat dikatakan sebagai penghubung suatu aplikasi dengan aplikasi lainnya yang memungkinkan programmer menggunakan system function.

\section{II.4 Phonegap}

Menurut Wahana Komputer (2014) PhoneGap adalah sebuah kerangka kerja/framework open source untuk membuat aplikasi yang dapat dijalankan pada banyak perangkat mobile. PhoneGap menggunakan bahasa pemrograman web, yaitu HTML, CSS dan JavaScript sebagai bahasa utama. Fitur hardware yang didukung Phonegap API: Geolocation, Accelerometer,Camera, Compass, Contact, File, Media, Network, Notification (alert), Notification (sound), Notification (vibration), Storage.

Untuk membuat aplikasi mobile dengan PhoneGao, dibutuhkan software Development Kit (SDK) dari perangkat mobile tujuan. PhoneGap menggunan SDK tersebut ketika mengkompilasi kode program untuk perangkat mobile yang sesuai dengan SDK yang terpasang. Untuk membuat aplikasi location based service untuk informasi dan pencarioan lokasi wisata berbasis Android, dibutuhkan:

1. Android Software Development Kit.

2. Library PhoneGap.

3. Apache.

4. Node.js.

5. JDK.

\section{ANALISIS DAN PERANCANGAN}

\section{III.1 Deskripsi Umum}

Perangkat lunak yang dibangun merupakan aplikasi mobile berbasis client server. Perangkat lunak yang digunakan pada aplikasi informasi dan pencarian rute terdekat lokasi pariwisata di Kota Cimahi berbasis Location Based Service ini dititikberatkan pada pengambilan koordinat, perangkat lunak memanfaatkan GPS. Kemudian untuk mendapatkan peta dan rute, sistem menggunakan 
GoogleMap APIs dengan memberikan parameter koordinat bumi. Setelah mengirim parameter tersebut ke GoogleMap, maka GoogleMap server akan membalas berupa peta statik. Dalam pencarian rute, perangkat lunak mengirimkan dua koordinat bumi sebagai alamat awal dan alamat tujuan, kemudian GoogleMap Direction server akan membalas berupa data dan rute yang akan ditampilkan pada pengguna.

Dalam pencarian lokasi pariwisata di Kota Cimahi, perangkat lunak terhubung ke Google maps dengan mengirimkan parameter koordinat perangkat mobile. Setelah mengirimkan parameter tersebut, maka server akan membalas berupa data lokasilokasi pariwisata yang selanjutnya akan di-parsing oleh sistem dan ditampilkan kepada pengguna. Secara garis besar, perangkat lunak yang akan dibangun diarahkan agar dapat memenuhi fungsionalitas seperti pada tabel 2.

Tabel 2. Kebutuhan Fungsionalitas

\begin{tabular}{|c|c|c|c|}
\hline No & $\begin{array}{l}\text { Kode } \\
\text { Kebutuhan }\end{array}$ & $\begin{array}{l}\text { Nama } \\
\text { Kebutuhan }\end{array}$ & Keterangan \\
\hline 1 & ReqLBS-1 & $\begin{array}{l}\text { Mencari Lokasi } \\
\text { Pariwisata. }\end{array}$ & $\begin{array}{l}\text { Aplikasi ini } \\
\text { harus mampu } \\
\text { digunakan untuk } \\
\text { mencari lokasi- } \\
\text { lokasi } \\
\text { pariwisata. }\end{array}$ \\
\hline 2. & ReqLBS-2 & $\begin{array}{l}\text { Menampilkan } \\
\text { Informasi } \\
\text { Pariwisata. }\end{array}$ & $\begin{array}{l}\text { Aplikasi ini } \\
\text { harus mampu } \\
\text { digunakan untuk } \\
\text { menampilkan } \\
\text { informasi } \\
\text { pariwisata. }\end{array}$ \\
\hline 3. & ReqLBS-3 & $\begin{array}{l}\text { Menampilkan } \\
\text { lokasi pariwisata }\end{array}$ & $\begin{array}{l}\text { Aplikasi ini } \\
\text { harus mampu } \\
\text { digunakan untuk } \\
\text { menampilkan } \\
\text { lokasi } \\
\text { pariwisata. }\end{array}$ \\
\hline
\end{tabular}

Skema implementasi teknologi LBS pada aplikasi pencarian lokasi wisata berbasis android dapat dilihat pada gambar 1. Mula-mula perangkat pengguna akan memberikan mas ukan berupa permintaan rute. Permintaan ini diproses oleh jaringan komunikasi yang terhubung dengan internet untuk mencari posisi lokasi yang diminta. Selanjutnya, berdasarkan layanan posisi lokasi dari GoogleMaps API, akan diinformasikan lokasi pengguna dan lokasi obyek wisata terdekat. Informasi ini dilengkapi dengan konten seperti koordinat, nama lokasi dan alamat, dan akhirnya memberikan deskripsi grafis mengenai rute yang harus ditempuh.

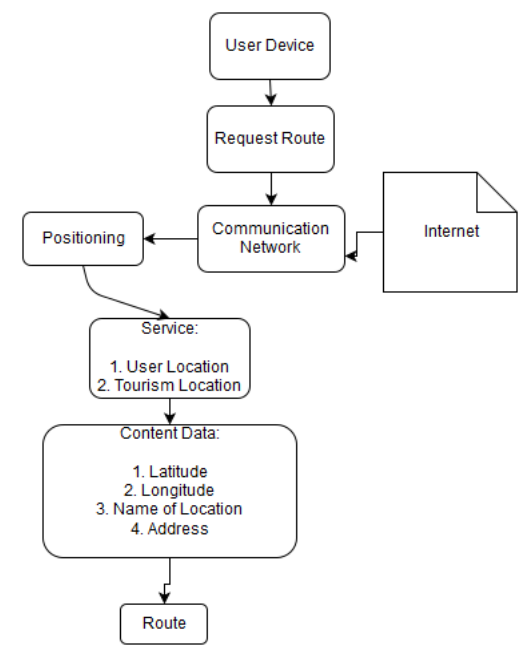

Gambar 1. Diagram Implementasi LBS Pada Aplikasi

Berdasarkan identifikasi kebutuhan fungsionalitas, dapat digambarkan fitur utama aplikasi melalui diagram use case seperti pada gambar 2.

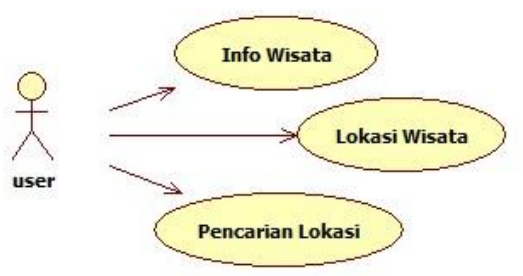

Gambar 2. Use Case Diagram

\section{III.2 Desain Sistem}

Berdasarkan use case diagram dan identifikasi data dan informasi yang harus ditampilkan, kemudian didefinisikan class diagram dan relasi antar class, seperti yang terlihat pada gambar 3 .

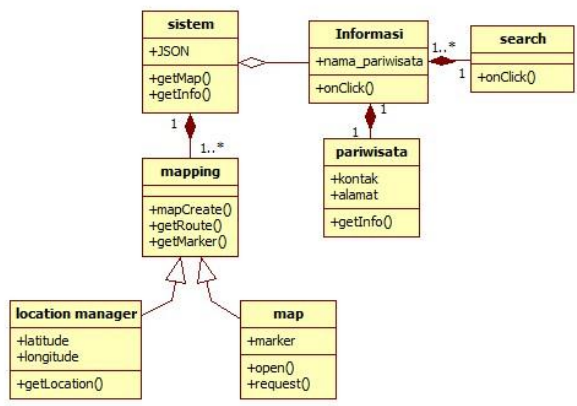

Gambar 3. Class Diagram

Nova Agustina, Slamet Risnanto, Irwin Supriadi 
Tabel 3 menampilkan deskripsi detil dari class yang akan diimplementasikan pada aplikasi

Tabel 3. Keterangan Class Diagram

\begin{tabular}{|c|c|c|}
\hline No & Nama Class & Keterangan \\
\hline 1 & Sistem & Merupakan kelas utama. \\
\hline 2 & Informasi & $\begin{array}{l}\text { Merupakan kelas yang menangani } \\
\text { informasi pariwisata. }\end{array}$ \\
\hline 3 & Pariwisata & $\begin{array}{l}\text { Merupakan kelas yang berisi } \\
\text { tentang informasi pariwisata. }\end{array}$ \\
\hline 5 & Search & $\begin{array}{l}\text { Merupakan kelas yang menangani } \\
\text { pemetaan. }\end{array}$ \\
\hline 6 & Map & $\begin{array}{l}\text { Merupakan kelas yang menangani } \\
\text { antarmuka peta. }\end{array}$ \\
\hline 7 & Mapping & $\begin{array}{l}\text { Merupakan kelas khusus yang } \\
\text { menangani antarmuka peta lokasi } \\
\text { user, wisata dan informasi rute } \\
\text { perjalanan ke tempat pariwisata. }\end{array}$ \\
\hline 8 & Location Manager & $\begin{array}{l}\text { Merupakan kelas yang yang } \\
\text { menentukan lokasi. }\end{array}$ \\
\hline
\end{tabular}

\section{III.3 Implementasi Sistem}

Proses selanjutnya adalah mencari rute dari lokasi user menuju lokasi pariwisata yang dipilih yang akan ditampilkan pada antarmuka user. Berikut ini merupakan tampilan listing kodenya:

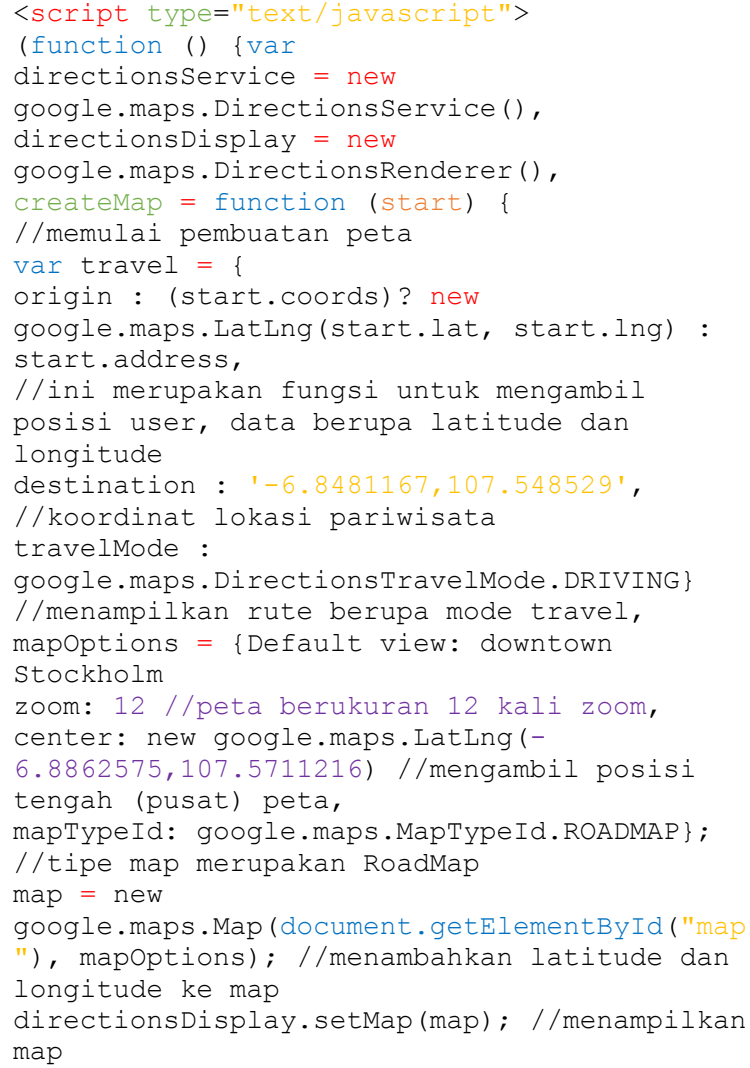

directionsDisplay. setPanel (document.getEleme ntById("map-directions")) ; /membuat rute dari 2 buah data latitude dan longitude directionsService.route (travel, function(result, status) \{ if (status $===$ google.maps.Directionsstatus.oK) \{ directionsDisplay.setDirections (result);//ji ka titik koordinat ditemukan, maka rute akan ditampilkan

\}) ) $;$; </script $>$

Hasil eksekusi script di atas dapat dilihat seperti contoh pada gambar 4. Gambar 3 menampilkan rute untuk mencapai lokasi Alam Wisata (B) dari lokasi asal pengguna (A). Tampilan aplikasi dibagi menjadi dua kolom utama yaitu kolom untuk menampilkan peta yang dilengkapi dengan tombol untuk memperbesar dan memperkecil peta (+/-), kembali ke menu utama dan informasi beranda dan kontak. Kolom kedua menampilkan rute yang direkomendasikan untuk mencapai tujuan obyek wisata yang dicari.

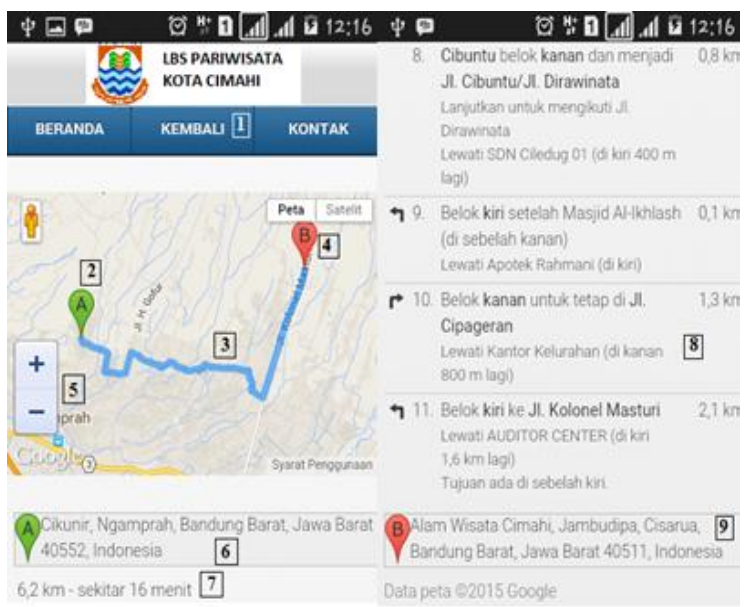

Gambar 4. Tampilan antarmuka rute menuju lokasi pariwisata

Hasil implementasi di atas menunjukkan bahwa pemanfaatan GoogleMap APIs pada aplikasi berbasis peta di Android sangat memudahkan pengembangan aplikasi berbasis LBS ini. Kendala yang mungkin terjadi di lapangan adalah jika daerah yang dituju merupakan daerah yang belum tercatat secara rinci pada Google Maps, sehingga sulit diperoleh peta yang akurat. Kendala lainnya adalah jika pengguna berada pada daerah dengan signal telekomunikasi yang kurang baik, sehingga identifikasi koordina lokasi maupun proses penampilan rute perjalanan akan memakan waktu. 


\section{EVALUASI IMPLEMENTASI}

Guna menguji respon pengguna atas penggunaan dan pemanfaatan aplikasi ini, dilakukan serangkaian kuisioner dan wawancara kepada 20 pengguna. Tujuan kuisoner ini untuk mengevaluasi sejauh mana aplikasi dapat membantu pengguna dalam mencari lokasi obyek wisata.

Kuesioner terdiri dari 5 pertanyaan yang dapat dijadikan sample untuk mengetahui pendapat langsung dari responden. Responden yang dipilih untuk mengisi kuesioner tersebut merupakan orangorang yang kurang mengetahui lokasi-lokasi pariwisata dan juga rute menuju lokasi pariwisata yang berada di Kota Cimahi. Tabel 4 Berikut ini adalah rincian dari item-item kuesioner yang diberikan kepada responden.

Tabel 4. Kuesioner Aplikasi

\begin{tabular}{|c|c|c|}
\hline No & Pertanyaan & Tidak \\
\hline 1 & $\begin{array}{l}\text { Apakah aplikasi } \\
\text { digunakan? }\end{array}$ & \\
\hline 2 & $\begin{array}{l}\text { Apakah aplikasi ini dapat membantu } \\
\text { anda untuk mencari lokasi } \\
\text { pariwisata di kota Cimahi? }\end{array}$ & \\
\hline 3 & $\begin{array}{l}\text { Apakah rute yang ditampilkan untuk } \\
\text { menuju lokasi pariwisata tersebut } \\
\text { akurat dan mudah dimengerti? }\end{array}$ & \\
\hline 4 & $\begin{array}{l}\text { Apakah dengan adanya aplikasi ini } \\
\text { dapat memberikan informasi lebih } \\
\text { akurat? }\end{array}$ & \\
\hline 5 & $\begin{array}{l}\text { Apakah informasi yang disampaikan } \\
\text { akurat? }\end{array}$ & \\
\hline
\end{tabular}

Tabel 5 menampilkan hasil perhitungan dari kuesioner aplikasi location based service untuk informasi dan pencarian lokasi pariwisata di Kota Cimahi. Perhitungan persentasi dilakukan dengan persamaan (2) :

Hasil presentase $=(\mathrm{JPR} / \mathrm{JR}) \mathrm{X} 100 \%$

dengan:

$\mathrm{JPR}=$ Jumlah Penilaian Responden

$\mathrm{JR}=$ Jumlah Responden

Berdasarkan hasil Kuisioner pada tabel 5 dapat dilihat bahwa 50 responden memberikan apresiasi positif sebesar $95.6 \%$ terhadap Aplikasi Location Based Service untuk informasi dan pencarian lokasi pariwisata di Kota Cimahi berbasis Android. Dengan demikian dapat diambil kesimpulan bahwa dengan adanya aplikasi location based service untuk informasi dan pencarian lokasi pariwisata di Kota
Cimahi ini dapat membantu user untuk mencari informasi dan lokasi-lokasi pariwisata di kota Cimahi. Selain itu rute yang ditampilkan dapat membantu mengarahkan user menuju lokasi pariwisata yang dituju

Tabel 5. Hasil Data Kuisioner

\begin{tabular}{cclll}
\hline \hline $\begin{array}{l}\text { No } \\
\text { Pertan } \\
\text { yaan }\end{array}$ & jml & Presentase & Jml & Presentase \\
\cline { 2 - 5 } & & & & \\
\hline 1 & 50 & $100 \%$ & 0 & $0 \%$ \\
2 & 50 & $100 \%$ & 0 & $0 \%$ \\
3 & 48 & $96 \%$ & 2 & $4 \%$ \\
4 & 46 & $92 \%$ & 4 & $8 \%$ \\
5 & 45 & $90 \%$ & 5 & $10 \%$ \\
Total & $\mathbf{2 3 9}$ & $\mathbf{9 5 . 6 \%}$ & $\mathbf{1 1}$ & $\mathbf{4 . 4 \%}$ \\
\hline \hline
\end{tabular}

\section{KESIMPUlan DAN SARAN}

\section{V.1 Kesimpulan}

Berdasarkan uraian pada bagian sebelumnya maka dapat ditarik beberapa kesimpulan mengenai hasil dari implementasi dan pengujian aplikasi Location Based Service untuk informasi dan pencarian lokasi pariwisatadi kota Cimahi sebagai solusi atas permasalahan yang ada, yaitu:

1. Aplikasi yang dibuat mampu membantu masyarakat menemukan lokasi pariwisata yang ada di Kota Cimahi melalui perangkat mobile Android.

2. Aplikasi yang dibuat mampu membantu masyarakat menemukan rute terdekat menuju lokasi pariwisata yang telah dipilih dan menampilkannya pada perangkat mobile Android, beserta penanda rute yang dapat ditempuh.

3. Hasil uji aplikasi menunjukan adanya kekurangan, yaitu dalam pencarian lokasi dan rute ke lokasi, user memerlukan adanya koneksi data. Apabila koneksi data kurang baik, penenetuan lokasi user maupun lokasi pariwisata terkesan lama bahkan terkadang tidak dapat membaca lokasi user maupun lokasi pariwisata. Selain itu, penunjuk arah ke lokasi pariwisata hanya berupa list text yang harus dibaca oleh user, hal tersebut kurang efektif untuk user yang sedang berkendara.

Nova Agustina, Slamet Risnanto, Irwin Supriadi

Jurnal Ilmiah Teknologi Informasi Terapan

Volume III, No 1, 15 Desember 2016 


\section{V.2 Saran}

Saran yang ingin disampaikan peneliti untuk mengatasi kekurangan aplikasi yang dibuat dan untuk kepentingan pengembangan lebih lanjut bagi para pengembang adalah:

1. Untuk mengurangi adanya kekurangan pada aplikasi ini maka aplikasi ini dapat dikembangkan lebih lanjut dengan menambahkan database SQLite pada aplikasi ini agar aplikasi dapat digunakan secara offline.

2. Untuk meningkatkan performa fungsionalitas aplikasi ini, dapat ditambahkan fitur navigasi suara dan fitur navigasi jalur transportasi umum bagi user.

3. Pengembangan lebih lanjut lagi dapat dilakukan dengan menambahkan fungsi untuk menggunakan aplikasi dengan berbagai macam bahasa agar para wisatawan asing yang sedang berada di wilayah Kota Cimahi dan memerlukan aplikasi ini dapat menggunakannya lebih mudah.

4. Pengembangan selanjutnya aplikasi LBS untuk informasi dan pencarian lokasi pariwisata bukan hanya di Kota Cimahi, melainkan lebih meluas untuk seluruh kota di Indonesia.

\section{REFERENSI}

BPS Provinsi Jawa Barat, 2012. Jawa Barat In Figures. Diambil dari: http://www.jabar prov.go.id/.../dda2012.pdf (11 April 2016).

Growth from Knowledge, 2015. Android Opera Dominasi Smartphone Indonesia. Diambil dari: http://id.techinasia.com/android-operadominasi-smartphone-indonesia-2014/ (10 April 2016).

Kusuma, Wahyu, Siti Eriza Mulyani dan Any Yapie. 2013. Aplikasi Location Based Service Taman Mini Indonesia Indah (TMII) Berbasis Android. Yogyakarta: Seminar Nasional Aplikasi Teknologi Informasi 2013. ISSN: 1907-5022.

Mulyanto, Aunur Rofiq. 2008. Rekayasa Perangkat Lunak.Jakarta: Direktorat Pembinaan Sekolah Menengah Kejuruan, Direktorat Manajemen Pendidikan Dasar dan Menengah, Departemen Pendidikan Nasional.

Murya, Yosef. 2013. Pemrograman Android Black Box. Yogyakarta: Jasakom.
Safaat, Nazruddin 2013. Aplikasi Berbasis Android. Bandung: Informatika.

Sugiarto, Imam. 2013. Aplikasi Pencarian Lokasi Terdekat Pelayanan Kesehatan Berbasis Android Di Yogyakarta. Diambil dari: http://repository.amikom.ac.id/.../Publikasi_ 10_11.3563.pdf (15 April 2016, 06:26).

Studiawan, Muchamad Husni, Muchamad Iqbal. 2012.Implementasi Klien SIP Berbasis Web Menggunakan HTML 5 dan Node.js. Diambil dari: http://ejurnal.its.ac.id /.../ download/643/377 (02 April 2016, 17:23).

Taylor, George dan Geoff Blewitt. 2006. Intelligent Positioning GIS-GPS Unfication. US: Willey.

Wahana Komputer, 2014. Mobile App Development With Phonegap. Yogyakarta: Andi. 